\title{
Physical characteristics of nanoemulsion from chitosan/nutmeg seed oil and evaluation of its coating against microbial growth on strawberry
}

\author{
Horison, R., Sulaiman, F.O., Alfredo, D. and *Wardana, A.A. \\ Food Technology Department, Faculty of Engineering, Bina Nusantara University, Jakarta, Indonesia \\ 11480
}

\author{
Article history: \\ Received: 2 March 2019 \\ Received in revised form: 21 \\ May 2019 \\ Accepted: 21 May 2019 \\ Available Online: 17 June \\ 2019
}

\section{Keywords:}

Edible coating,

Chitosan,

Nutmeg seed oil,

Microbial,

Strawberry,

Nanoemulsion

\begin{abstract}
The objectives of this research were to characterize nanoemulsion from chitosan/nutmeg seed oil and to evaluate its coating on fresh strawberry which stored at $10^{\circ} \mathrm{C}$ for 5 days. The ultraturrax and high-pressure homogenizer were used to prepare $1.34 \pm 0.25$ $5.79 \pm 1.61 \mathrm{~nm}$ of nanoemulsion size which confirmed by particle size analyzer. The morphology observed by SEM that exhibited the oil globules were covered by chitosan. They were aggregated and rough droplets. Interactions among the materials were observed using FTIR which led to the presence of a new peak at $1736 \mathrm{~cm}^{-1}$. The coated strawberry by high-pressure homogenizer-emulsion showed the best result suppressing microbial $(2.41 \pm 0.01)$ and mould-yeast $(2.78 \pm 0.10)$ growth at the end of storage compared to control which were $3.37 \pm 0.02$ and $3.69 \pm 0.14$ for microbial and mould-yeast count respectively.
\end{abstract}

DOI:

https://doi.org/10.26656/fr.2017.3(6).159

\section{Introduction}

Strawberry fruit (Fragaria ananassa) is nonclimacteric and highly susceptible to fungal decay, mechanical injury, and water loss during storage (Gol et al., 2013). Post-harvest loss of strawberry during handling, transportation, and storage is a serious problem. Development of edible coating has been studied continuously to serve an inhibition of fresh fruit decay and deterioration. It is an eco-friendly breakthrough applied to various food including postharvest commodities (Aulakh and Regmi, 2013). Among many kinds of fruits, strawberry is one of the most appropriate to be coated by edible coating because the customer generally consumes it without peeling (ready to eat).

The materials for making edible coating are classified into hydrocolloids (starch and protein), lipids (fatty acids and waxes) and composites. Carboxymethyl cellulose, starch, gelatine, alginate, and pullulan have been studied as coating matrix to maintain the quality of strawberry (García et al., 1998; Li et al., 2017; Aitboulahsen et al., 2018; Yan et al., 2019). Another potential polymer of hydrocolloid is chitosan, an edible, biocompatible, and non-toxic amino polysaccharide made from deacetylation of chitin (Romanazzi et al., 2013). The use of chitosan in edible layers also provides a barrier effect on both gas and water vapor (Butler et al., 1996). Previous studies revealed that chitosan coating suspension extended the shelf-life of guava and strawberry fruit for 7 and 8 days respectively (Petersen et al., 1999; Hernández-Muñoz et al., 2008). Amino groups of chitosan are able to interact with the electronegative charges of microbial cell surface resulting in the leakage of intracellular components (Rabea et al., 2003). However, single chitosan coating has limited inhibition to particular microorganism and poor barrier properties to the gas (Ravi, 2000).

The application of chitosan coating needs to combine with other substances such as resins, essential oils, polysaccharides and proteins to improve its functional properties. Kittur et al. (2001) and Zhu et al. (2008) utilized chitosan coating to inhibit respiration rate, maintain hardness, prevent discoloration, prevent Colletotrichum gloeosporioides invasion and reduce the alteration of ascorbic acid of mango. The incorporation of essential oils in chitosan-based material has been also applied as an alternative such as lemon (Perdonesa et al., 2012), peppermint (Picard et al., 2013), and Curcuma longa L. (Yusof et al., 2018) essential oil to keep quality of fresh fruits. Spices essential oil have been also utilized as both food and flavouring agent since a long time ago, and as functional substances and food preservatives in recent years (Lai and Roy, 2004; Thanoon et al., 2013; Nabavi et al., 2015). Nutmeg is one of the Indonesian 
local natural resources that can be further processed into oil which has antimicrobial activity. The concentration $(5 \%)$ exhibited a maximum inhibitory zone $(16.8 \mathrm{~mm})$ against Staphylococcus aureus (Zheng et al., 2016). Essential oil contained nutmeg (5-15\%) are mostly consisted of camphene or sabinene, d-pinene, dipentene, d-linalool, d-borneol,i-terpineol, geraniol, myristicine, safrole, eugenol, and isoeugenol which antimicrobial activity was primarily caused by pinene component (Takikawa et al., 2002; Lai and Roy, 2004).

Nowadays, nanotechnology has gained great attention as a new generation of microtechnology, with one potential use being nanoemulsion. Nanoemulsion provides a potential carrier applied for food commodities due to its ability to optimize the dispersion of active substances (Meindrawan et al., 2018; Wardana et al., 2018; Yuliani et al., 2018). The formulation of various emulsion types can be applied as food coatings, particularly for postharvest products such as papaya, strawberry, and mango (Zhu et al., 2008; Perdonesa et al., 2012; Picard et al., 2013). It might offer a breakthrough method in maintaining the shelf life and quality of strawberry. The aims of this study were to characterize nanoemulsion from chitosan/nutmeg seed oil and to evaluate its coating on fresh strawberry stored at $10^{\circ} \mathrm{C}$ for 5 days.

\section{Materials and methods}

\subsection{Materials}

Fresh strawberry was obtained from a local store (Total Fresh Fruit) in Tangerang, Indonesia. Chitosan and nutmeg seed oil were obtained from M \& H Farm, Bogor, Indonesia. The emulsifier and chitosan solvent used was tween 80 and acetic acid respectively purchased from Merck (Germany). Total aerobic microbial and mould-yeast count were conducted using Plate Count Agar (PCA) (Sigma-Aldrich, Germany) and Potato Dextrose Agar (PDA) (Sigma-Aldrich, Germany), respectively.

\subsection{Preparation of nanoemulsion and samples}

Chitosan $3.5 \mathrm{~g}, 2.5 \mathrm{~mL}$ nutmeg seed oil, $100 \mathrm{~mL}$ acetic acid $1 \%$ and $5 \mathrm{~mL}$ Tween 80 were blended in with constant stirring using magnetic stirrer at temperature $40^{\circ} \mathrm{C}$ for $2 \mathrm{hrs}$ which is further stated as conventional emulsion (CE). Then, it was cooled at $29 \pm 1^{\circ} \mathrm{C}$. UTREmulsion was produced by further homogenizing of $\mathrm{CE}$ using ultraturrax $24000 \mathrm{rpm}$ for 3 mins at $29 \pm 1{ }^{\circ} \mathrm{C}$. While, HPH-Emulsion was made by advanced processing which was homogenized with extremely high -pressure using instrument High-Pressure Homogenizer (HPH), GEA Niro Soavi (Italy) with a pressure 200 bar, 1 cycle. Subsequently, the fresh strawberries were dipped for $30 \mathrm{~s}$ in the different coating suspensions and drained following Hernández-Muñoz et al. (2008) with slight modification. After being air-dried, the fruits were placed on the sterile disposable petri dish, One Med, diameter $90 \mathrm{~mm}$. All samples were stored at $10^{\circ} \mathrm{C}$ for 5 days.

\subsection{Characterization of nanoemulsion}

The size distribution of the emulsion system was done to evaluate the emulsion type of each suspension (UTR-Emulsion and HPH-Emulsion) based on their size of emulsion droplets formed. The size distribution of droplets was characterized using Particle Size Analyzer (PSA), Zetasizer (model Nano ZS series Malvern Instruments, UK). The $1 \mathrm{~mL}$ emulsion suspension was placed into polystyrene micro cuvet with the detector angle $173^{\circ}$. The measurement was performed with three replications at temperature $25^{\circ} \mathrm{C}$ for $50 \mathrm{~s}$ to observe the emulsion stability of edible coating suspension.

The morphology of the emulsion droplets contained in the edible coating suspension was observed using a scanning electron microscopy (SEM), JEOL 6010 LA Benchtop. Beforehand, all kinds of emulsion suspension were poured on the sterile disposable petri dish, One Med, diameter $90 \mathrm{~mm}$. Then, they were dried in an oven at temperature $40^{\circ} \mathrm{C}$ for $24 \mathrm{hrs}$ to form thin films. The films were coated with gold and confirmed by using SEM under an acceleration voltage of $20 \mathrm{kV}$, at a magnification of 1000x and 2000x.

Fourier-Transform Infrared Spectroscopy (FTIR) analysis was performed to detect the functional groups of each sample used to produce nanoemulsion and to study the interactions among them. The samples were subjected to FTIR (Thermo Fisher Scientific, iN10) in the scanning range of $4000-500 \mathrm{~cm}^{-1}$.

\subsection{Evaluation of nanoemulsion against microbial growth on strawberry}

Aerobic plate count and mould-yeast count were detected following Frazier and Westhoff (1998) method with slight modification, by diluting $5 \mathrm{~g}$ of samples in 45 $\mathrm{mL}$ of $0.1 \%$ peptone water, followed by homogenization in a vortex mixer. Further decimal dilutions were made from this $10^{-1}$ dilution. Subsequently, serial dilutions were performed using $0.1 \%$ peptone water and then samples were plated in duplicate. Aerobic plate count and mould-yeast count were performed using aerobic PCA and PDA, respectively. All plates were then incubated at $35-37^{\circ} \mathrm{C}$ and colonies of total aerobic microbial and mould-yeast count were calculated after 48 and $72 \mathrm{hrs}$ respectively. The results were expressed as $\mathrm{CFU} / \mathrm{g}$. 


\subsection{Statistical analysis}

The data obtained in this study were evaluated by Ttest for particle size distribution and analysis of variance (ANOVA) for total aerobic microbial and mould-yeast count using SPSS (Statistical Product and Service Solutions) version 16.0 and followed by Duncan's Multiple Range Test (DMRT) at a significance level of $\mathrm{p}<0.05$.

\section{Results and discussion}

\subsection{Characterization of nanoemulsion}

Nanoemulsion manufactured from chitosan and nutmeg seed oil blends has successfully formed a particle size in the range of $1.34-5.79 \mathrm{~nm}$. Figure 1 exhibits the size distribution spectra of emulsion system determined by measuring the PSA.
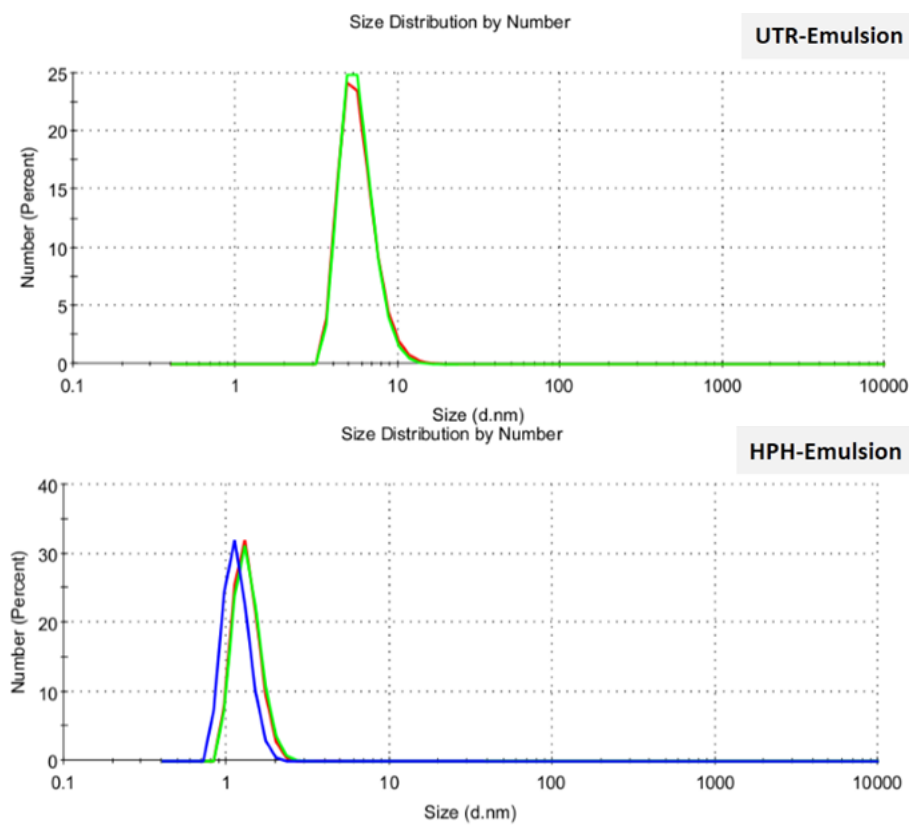

Figure 1. Size distribution spectra of chitosan/nutmeg seed oil blends using PSA

HPH-Emulsion has the smallest diameter average $(1.34 \pm 0.25 \mathrm{~nm})$ compared to another suspension. Moreover, the visual appearance of HPH-Emulsion appeared brighter than UTR-Emulsion (Figure 2a) because nanoemulsion could enhance the dispersion of formulation so that a larger specific surface area formed offering a brighter colour (Çinar, 2017). In the HPH system, a blend of oil, water and surfactant is pushed passing a small gap, typically $1-10 \mathrm{~mm}$, where droplets undergo extremely shear and elongational stress resulting enhancement of pressure drop up to a few thousand bars (Mason et al., 2006; Floury et al., 2009; Helgeson et al., 2012). Due to the high level of pressure inside the instrument, droplets undergo deformation and alteration into smaller form compared to UTR-Emulsion $(5.79 \pm 1.61 \mathrm{~nm})$. While UTR-Emulsion is based on the

moving of the rotor with a very high circumferential speed $(24000 \mathrm{rpm})$. The suction produced pulled the sample into the rotor and pushed it to the outside. This process crushed the liquid droplets resulting in the sample's dispersion with smaller size. A previous study stated that the most dominant factors affecting the particle size reduction which were the time and speed of homogenization (Silva et al., 2011). Another method has been reported by Ghaderi-Ghahfarokhi et al. (2017) in which nanoparticles with the size distribution of 235.6 $\mathrm{nm}$ were produced by incorporating cinnamon essential oil in chitosan matrix using an ultrasonic water bath for 1 hr.

(a)
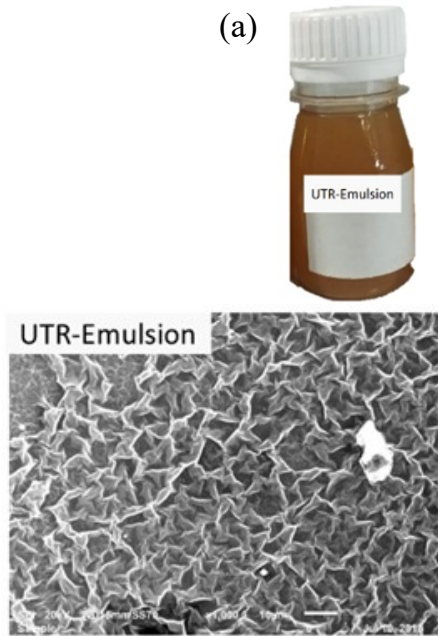

HPH-Emulsion

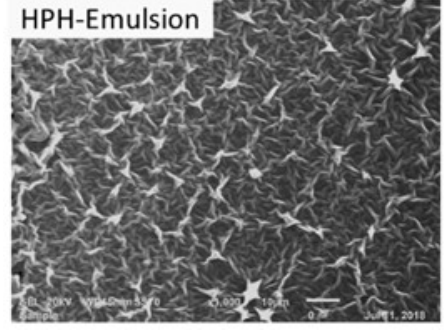

Figure 2. (a) Visually comparison of nanoemulsion between UTR-Emulsion and HPH-Emulsion and (b) the morphology of the emulsion droplets contained in the thin film at $1000 \mathrm{x}$ and 2000x magnification

SEM was used to confirm the particle size distribution of nanoemulsion. Morphology images of the thin film in this study (Figure 2b) show unclearly emulsion droplets shape which is generally exhibited by spherical droplets and smooth in nature of oil globules in edible coating suspension. That result was presumably that oil globules in nano-scale are covered by chitosan. They aggregated in the form of thin fused and rough droplets. In comparison, a previous researcher who developed nanoemulsion sample containing $\beta$-carotene; nanodrops were observed using SEM with spherical shape and smooth surface (Hasani et al., 2015). Another study found that an atomic force microscope analysis clearly exhibited the spherical shape and nanosized structure of individual particles of cinnamon essential oil in the chitosan matrix (Ghaderi-Ghahfarokhi et al., 
2017). Another study also revealed that encapsulation containing repaglinide did not affect the morphology of nanoemulsion (Nanjwade et al., 2013).

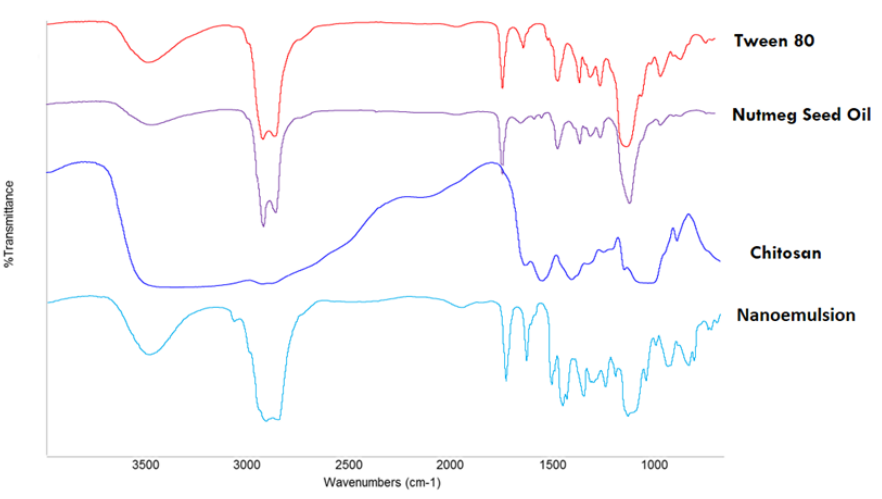

Figure 3. FTIR spectra

FTIR spectroscopy was used to observe the interactions among materials of nanoemulsion. Figure 3 shows FTIR spectra of chitosan, Tween 80 , nutmeg seed oil and nanoemulsion. It could be seen that the peak of $\mathrm{N}$ $-\mathrm{H}$ bending in chitosan reached at $1552 \mathrm{~cm}^{-1}$ is shifted to $1633 \mathrm{~cm}^{-1}$. The bands arising at the range of $2700-3000$ $\mathrm{cm}^{-1}$ in the spectrum of nanoemulsion are attributed the stretching vibrations of $-\mathrm{CH}_{2}\left(2924 \mathrm{~cm}^{-1}\right)$ and $-\mathrm{CH}_{3}$ $\left(2857 \mathrm{~cm}^{-1}\right)$ from tween 80 and nutmeg seed oil. The peak $3498 \mathrm{~cm}^{-1}$ of nanoemulsion is inferred to $\mathrm{O}-\mathrm{H}$ stretching vibration which is shifted from $3949 \mathrm{~cm}^{-1}$ (Tween 80) and $3350 \mathrm{~cm}^{-1}$ (chitosan). Furthermore, the nanoemulsion leads to the presence of a new peak at $1736 \mathrm{~cm}^{-1}$. It is in accordance with the previous study when the essential oil was incorporated into chitosan films (Cerqueira et al., 2012; Sugumar et al., 2015).

\subsection{Evaluation of strawberry coating with nanoemulsion}

Table 1. Total aerobic microbial and mould-yeast count of samples for 5 days

\begin{tabular}{ccc}
\hline Sample & $\begin{array}{c}\text { Microbial count } \\
(\log \text { CFU/g) }\end{array}$ & $\begin{array}{c}\text { Mould-yeast count } \\
(\log \text { CFU/g) }\end{array}$ \\
\hline Pre treatment (day 0) & $4.76 \pm 0.04^{\mathrm{a}}$ & $4.67 \pm 0.01^{\mathrm{a}}$ \\
Control & $3.37 \pm 0.02^{\mathrm{b}}$ & $3.69 \pm 0.14^{\mathrm{b}}$ \\
UTR-Emulsion & $2.49 \pm 0.07^{\mathrm{c}}$ & $2.93 \pm 0.04^{\mathrm{c}}$ \\
HPH-Emulsion & $2.41 \pm 0.01^{\mathrm{c}}$ & $2.78 \pm 0.10^{\mathrm{c}}$ \\
\hline
\end{tabular}

Application of nanoemulsion edible coating led to a reduction of the microbial counts at the end of storage compared to control as shown in Table 1. The microbial and mould-yeast counts of fresh strawberry reached 2.41 - 3.37 and $<0.17$ - $3.69 \log \mathrm{CFU} / \mathrm{g}$, respectively. However, those are still below the safe threshold for consumption which was regulated by Indonesia National Agency of Drug and Food Control (BPOM) that is the maximum of microbial contamination on fruit is $5.00 \mathrm{log}$ CFU/g (BPOM, 2009). On day 5, nanoemulsion coating treatments on strawberry suppressed both microbial and mould-yeast growth compared to control. This is due to the nanoemulsion from chitosan combined with nutmeg seed oil filler which has antibacterial and antifungal abilities, respectively. Several mechanisms of nutmeg seed oil as antimicrobial have been reported, such as by inactivating microbial adhesion, enzymes, and cell envelope proteins (Gupta et al., 2008). While, the specific antimicrobial activity of chitosan has been many previously studied, such as relating to its molecular weight, deacetylation degree, and an alteration in cell permeability (Devlieghere et al., 2004). Chitosan which has low molecular weight could pass into the hypha of Fulvia fulva observed clearly using confocal laser scanning microscopy of fluorescein-labelled chitosan ( $\mathrm{Li}$ et al., 2011). Furthermore, the previous author revealed that interactions occurring between its amino groups and the electronegative charges on the surface of microbial cell tend to lead to the leakage of intracellular constituents (Rabea et al., 2003). The colour of strawberry changes from light red to dark red. On day 5 of storage, HPH-Emulsion coating could still maintain the skin rigidity and colour (Figure 4).

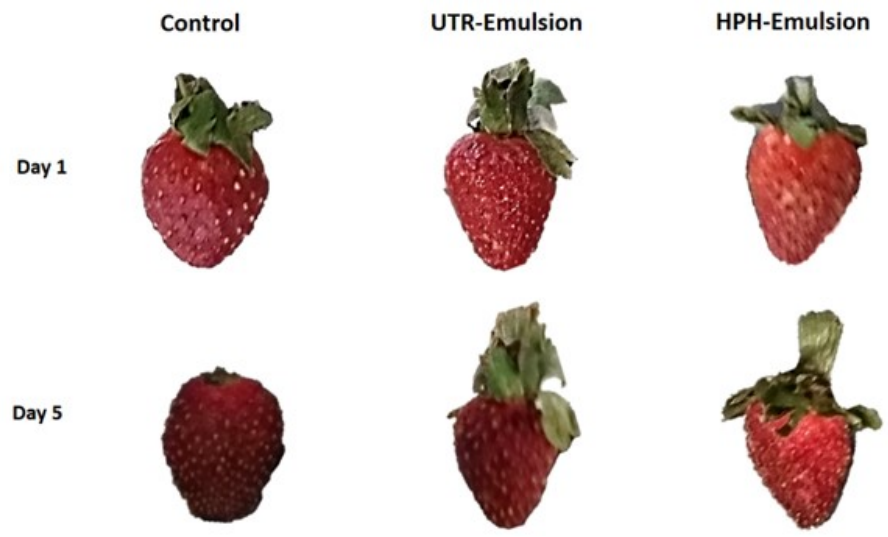

Figure 4 . Strawberry appearance during storage at $10^{\circ} \mathrm{C}$ for 5 days

The droplet size of nanoemulsion also may affect in inhibiting microbial growth as demonstrated in Table 1. The coated sample by HPH-Emulsion has the highest inhibition of microbial growth. However, all formulations exhibit a beneficial effect against total microbial and mould-yeast growth compared to control. It is in line with the previous study which reported microbial growth inhibition in beef patties by applying nanoemulsion of cinnamon essential oil/chitosan as a coating (Ghaderi-Ghahfarokhi et al., 2017). Several mechanisms have been reported by previous studies including that essential oil encapsulation at the nanoscale could enhance the antimicrobial activity. It is because there is an increase in the content of the bioactive compounds in the area which microorganisms are located (Weiss et al., 2009; Donsì et al., 2011).

\section{Conclusion}

Chitosan and nutmeg seed oil had potential as an 
antimicrobial compound. They could apply on strawberry in the form of nanoemulsion. Nanoemulsion made by using HPH had a smaller particle size confirmed by PSA. SEM observation shows unclearly emulsion droplets which presumably oil globules are covered by chitosan matrix. Also, it led to the presence of a new peak at $1736 \mathrm{~cm}^{-1}$ confirmed by FTIR. Smaller particle size of the emulsion has a larger surface area which increased the effectiveness in inhibiting microbial and mould-yeast growth on strawberry. This finding could be an alternative to maintain the quality of postharvest commodities during the 5 days storage.

\section{Acknowledgments}

We thank the Ministry of Research, Technology Higher Education of the Republic of Indonesia which provide the funding of this research through the grant of Student Creativity Program - Research 2018 (015/KM/ $\mathrm{PKM} / 2018$ ).

\section{References}

Aitboulahsen, M., Zantar, S., Laglaoui, A., Chairi, H., Arakrak, A., Bakkali, M. and Zerrouk, M.H. (2018). Gelatin-based edible coating combined with Mentha pulegium essential oil as bioactive packaging for strawberries. Journal of Food Quality, 5, 1-7. https:// doi.org/10.1155/2018/8408915

Aulakh, J. and Regmi, A. (2013). Post-harvest food losses estimation - development of consistent methodology. In Selected Poster Prepared for Presentation at the Agricultural and Applied Economics Association's AAEA and CAES Joint Annual Meeting. 4 - 6 August 2013. Washington DC: AAEA.

Butler, B.L., Vergano, P.J., Testin, R.F., Bunn, J.M. and Wiles, J.L. (1996). Mechanical and barrier properties of edible chitosan films as affected by composition and storage. Journal of Food Science, 61(5), 952955.

https://doi.org/10.1111/j.13652621.1996.tb10909.x

Cerqueira M.A., Souza B.W.S., Teixeira J.A. and Vicente A.A. (2012). Effect of glycerol and corn oil on physicochemical properties of polysaccharide films - A comparative study. Food Hydrocolloids, 27 (1), 175-184. https://doi.org/10.1016/ j.foodhyd.2011.07.007

Çinar, K. (2017). A review on nanoemulsions: preparation methods and stability. Trakya University Journal of Engineering Sciences, 18(1), 73-83.

Devlieghere, F., Vermeulen, A. and Debevere, J. (2004). Chitosan: antimicrobial activity, interactions with food components and applicability as a coating on fruit and vegetables. Food Microbiology, 21(6), 703714. https://doi.org/10.1016/j.fm.2004.02.008

Donsì, F., Annunziata, M., Sessa, M. and Ferrari, G. (2011). Nanoencapsulation of essential oils to enhance their antimicrobial activity in foods. $L W T$ Food Science and Technology, 44(9), 1908-1914. https://doi.org/10.1016/j.lwt.2011.03.003

Floury, J., Bellettre, J., Legrand, J. and Desrumaux, A. (2009). Analysis of a new type of high-pressure homogeniser. A study of the flow pattern.Chemical Engineering Science, 59(4), 843-853. https:// doi.org/10.1016/j.ces.2003.11.017

Frazier, W.C. and Westhoff, D.C. (1998). Food Microbiology. 4th ed., p. 539. New York: McGraw Hill Book Co., Inc.

García, M.A., Martino, M.N. and Zaritzky, N.E. (1998). Plasticized starch-based coatings to improve strawberry (Fragaria $\times$ Ananassa) quality and stability. Journal of Agricultural and Food Chemistry, 46(9), 3758-3767. https:// doi.org/10.1021/jf980014c

Ghaderi-Ghahfarokhia, M., Barzegara, M., Saharia, M.A., Gavlighia, H.A. and Gardini, F. (2017). Chitosan-cinnamon essential oil nano-formulation: Application as a novel additive for controlled release and shelf life extension of beef patties. International Journal of Biological Macromolecules, 102, 19-28. https://doi.org/10.1016/j.jibiomac.2017.04.002

Gol, N.B., Patel, P.R. and Rao, T.V.R. (2013). Improvement of quality and shelf-life of strawberries with edible coatings enriched with chitosan. Postharvest Biology and Technology, 85, 185-95. https://doi.org/10.1016/j.postharvbio.2013.06.008

Gupta, C., Garg, A.P., Uniyal, R.C. and Kumara, A. (2008). Antimicrobial activity of some herbal oils against common food-borne pathogens. African Journal of Microbiology Research, 2(10), 258-261.

Hasani, F., Pezeshki, A. and Hamishehkar, H. (2015). Effect of surfactant and oil type on size droplets of $\beta$ -carotene-bearing nanoemulsions. International Journal of Current Microbiology Applied Sciences, 4 (9), 146-155.

Helgeson, M.E., Moran, S.E., An, H.Z. and Doyle, P.S. (2012). Mesoporous organohydrogels from thermogelling photo crosslinkable nanoemulsions. Nature Materials, 11(4), 344-352. https:// doi.org/10.1038/nmat3248

Hernández-Muñoz, P., Almenar, E., Valle, V.D., Velez, D. and Gavara, R. (2008). Effect of chitosan coating combined with postharvest calcium treatment on strawberry (Fragaria $\times$ ananassa) quality during refrigerated storage. Food Chemistry, 110(2), 428- 
35. https://doi.org/10.1016/j.foodchem.2008.02.020

Indonesia National Agency of Drug and Food Control (BPOM). (2009). Regulation of Indonesia national agency of drug and food control - Maximum level of microbiological and chemical contaminants in foods (No. HK.00.06.1.52.4011). Retrieved from BPOM website: http://codexindonesia.bsn.go.id/uploads/ download/Regulasi\%20Pangan\%20BPOM $\% 20 \mathrm{No} \%$ 20HK.00.06.1.52.4011.pdf.

Kittur, F.S., Saroja, N., Habibunnisa and Tharanathan, R. (2001). Polysaccharide-based composite coating formulations for shelf-life extension of fresh banana and mango. European Food Research and Technology, 213(4-5), 306-311. https:// doi.org/10.1007/s002170100363

Lai, P.K. and Roy, J. (2004). Antimicrobial and chemopreventive properties of herbs and spices. Current Medicinal Chemistry, 11(11), 1451-1460. https://doi.org/10.2174/0929867043365107

Li, M.Q., Chen, X.G., Liu J.M., Zhang W.F. and Tang X.X. (2011). Molecular weight-dependent antifungal activity and action mode of chitosan against Fulvia fulva (Cooke) Ciffrri. Journal of Applied Polymer Science, 119(6), 3127-3135. https://doi.org/10.1002/ app.31831

Li, L., Sun, J., Gao, H., Shen, Y., Li, C., Yi, P., He, X., Ling, D., Sheng, J., Li, J., Liu, G., Zheng, F., Xin, M., Li, Z. and Tang, Y. (2017). Effects of polysaccharide-based edible coatings on quality and antioxidant enzyme system of strawberry during cold storage. International Journal of Polymer Science, 2017, 1-8. https://doi.org/10.1155/2017/9746174

Mason, T.G., Wilking, J.N., Meleson, K., Chang, C.B. and Graves, S.M. (2006). Nanoemulsions: formation, structure, and physical properties. Journal of Physics: Condensed Matter, 18, 635-666. https:// doi.org/10.1088/0953-8984/18/41/R01

Meindrawan, B., Suyatma, N.E., Wardana, A.A. and Pamela, V.Y. (2018). Nanocomposite coating based on carrageenan and $\mathrm{ZnO}$ nanoparticles to maintain the storage quality of mango. Food Packaging and Shelf Life, 18, 140-146. https://doi.org/10.1016/ j.fpsl.2018.10.006

Nabavi, S.F., Di Lorenzo, A., Izadi, M., SobarzoSánchez, E., Daglia, M. and Nabavi, S.M. (2015). Antibacterial effects of cinnamon: From farm to food, cosmetic and pharmaceutical industries. Nutrients, 7(9), 7729-7748. https://doi.org/10.3390/ nu7095359

Nanjwade, B.K., Varia, P.J., Kadam, V.T., Srichana, T. and Kamble, M.S. (2013). Development and evaluation of nanoemulsion of repaglinide. JSM
Nanotechnology and Nanomedicine, 1(2), 10161024.

Perdonesa, A., Sánchez-Gonzáleza, L., Chiralt, A. and Vargas, M. (2012). Effect of chitosan-lemon essential oil coatings on storage-keeping quality of strawberry. Postharvest Biology and Technology, 70, 32-41.

https://doi.org/10.1016/

j.postharvbio.2012.04.002

Petersen K., Nielsen P.V., Bertelsen G., Lawther M., Olsen M.B., Nilsson N.H. and Mortensen G. (1999). Potential of biobased materials for food packaging. Trends in Food Science Technology, 10(2), 52-68. https://doi.org/10.1016/S0924-2244(99)00019-9

Picard, I., Hollingsworth, R.G., Wall, M., Nishijima, K., Salmieri, S., Vu, K.D. and Lacroix, M. (2013). Effects of chitosan-based coatings containing peppermint essential oil on the quality of postharvest papaya fruit. International Journal of Postharvest Technology and Innovation, 3(2), 178189. https://doi.org/10.1504/IJPTI.2013.055845

Rabea E.I, Badawy M.E.T., Stevens C.V., Smagghe G. and Steurbaut W. (2003). Chitosan as antimicrobial agent: applications and mode of action. Biomacromolecules, 4(6), 1457-1465. https:// doi.org/10.1021/bm034130m

Ravi, K.M.N.V. (2000). A review of chitin and chitosan applications. Reactive and Functional Polymers, 46 (1), 1-27. https://doi.org/10.1016/S1381-5148(00) 00038-9

Romanazzi, G., Feliziani, E., Santini, M. and Landi, L. (2013). Effectiveness of post-harvest treatment with chitosan and other resistance inducers in the control of storage decay of strawberry. Postharvest Biology and Technology, 75, 24-27. https://doi.org/10.1016/ j.postharvbio.2012.07.007

Silva, H.D., Cerqueira, M.A., Souza, B.W., Ribeiro, C., Avides, M.C., Quintas, M.A. and Vicente, A.A. (2011). Nanoemulsions of $\beta$-carotene using a highenergy emulsification-evaporation technique. Journal of Food Engineering, 102(2),130-135. https://doi.org/10.1016/j.jfoodeng.2010.08.005

Sugumar, S., Mukherjee, A. and Chandrasekaran, N. (2015). Eucalyptus oil nanoemulsion-impregnated chitosan film: antibacterial effects against a clinical pathogen Staphylococcus aureus, in vitro. International Journal of Nanomedicine, 10(Suppl. 1), 67-75. https://doi.org/10.2147/IJN.S79982

Takikawa, A., Abe, K., Yamamoto, M., Ishimaru, S., Yasui, M., Okuba, Y. and Yokoigawa, K. (2002). Antimicrobial activity of nutmeg against Escherichia coli 0157. Journal of Bioscience and Bioengineering, 94(4), 315-320. https:// 
doi.org/10.1016/S1389-1723(02)80170-0

Thanoon, S.G., Al-Refai, A.S. and Kamal, A. (2013). Antibacterial effect and healing potential of nutmeg oil for chemically induced oral ulcerations in rabbits. Zanco Journal of Medical Sciences, 17(2), 393-399. https://doi.org/10.15218/zjms.2013.0022

Wardana, A.A., Suyatma, N.E., Muchtadi, T.R. and Yuliani, S. (2018). Influence of $\mathrm{ZnO}$ nanoparticles and stearic acid on physical, mechanical and structural properties of cassava starch-based bionanocomposite edible films. International Food Research Journal, 25(5), 1837-1844.

Weiss, J., Gaysinksy, S., Davidson, M. and McClements, J. (2009). Nanostructured encapsulation systems: food antimicrobials. In Barbosa-Cánovas, G.V., Mortimer, A., Lineback, D., Spiess, W. and Buckle, K. (Eds.), IUFoST world congress book: Global issues in food science and technology., p. 425-479. Amsterdam: Elsevier Inc.

Yan, J., Luo, Z., Ban, Z., Lu, H., Li, D., Yang, D., Aghdam, M.S. and Li, L. (2019). The effect of the layer-by-layer (LBL) edible coating on strawberry quality and metabolites during storage. Postharvest Biology and Technology, 147, 29-38. https:// doi.org/10.1016/j.postharvbio.2018.09.002

Yuliani, S., Wardana, A.A., Meindrawan, B., Suyatma, N.E. andMuchtadi, T.R. (2018). Nanocomposite edible coating from cassava starch, stearic acid and $\mathrm{ZnO}$ nanoparticles to maintain quality of fresh-cut mango cv. Arumanis. The Annals of the University Dunarea de Jos of Galati Fascicle VI - Food Technology, 42(2), 49-58.

Yusof, N.M., Jai, J., Hamzah, F. and Pinijsuwan, S. (2018). Evaluation of the effect of Curcuma longa L. essential oil in chitosan-starch edible coating, presented at $7^{\text {th }}$ Nanoscience and Nanotechnology Symposium (NNS), Bandung City. Bristol: IOP Publishing. $\quad$ https://doi.org/10.1088/1757899X/395/1/012020

Zheng, J., Zhou, Y., Li, Y., Xu, D.P., Li, S. and Li, H.B. (2016). Spices for prevention and treatment of cancers. Nutrients, 8(8), 495-530. https:// doi.org/10.3390/nu8080495

Zhu, X., Wang, Q., Cao, J. and Jiang, W. (2008). Effects of chitosan on postharvest quality of mango (Mangifera indica L. cv. Tainong) fruit. Journal of Food Processing and Preservation, 32(5), 770-784. https://doi.org/10.1111/j.1745-4549.2008.00213.x 